\title{
Mineralogical and geochemical study \\ of modern stromatolites: clues to their formation and use as paleoenvironmental records.
}

\author{
JULIETTE DEBRIE ${ }^{1}$, DIMITRI PRÊT ${ }^{2}$, KARIM \\ BENZERARA $^{3}$, PIERRE SANS-JOFRE ${ }^{3}$ AND JEAN PAUL \\ SAINT MARTIN $^{4}$ \\ ${ }^{1}$ CNRS-IMPMC \\ ${ }^{2}$ IC2MP, Université de Poitiers \\ ${ }^{3}$ IMPMC, CNRS, Sorbonne Université, MNHN \\ ${ }^{4}$ CR2P, MNHN, Sorbonne université \\ Presenting Author: juliette.debrie@sorbonne-universite.fr
}

Carbonate biominerals are found throughout the history of the Earth and have received strong attention because they provide precious information about paleoenvironments. Although biomineralization has been extensively studied in eukaryotes forming skeletal biominerals, it is also widespread among Bacteria and Archaea. Mineral deposits resulting from organomineralization by diverse prokaryote-dominated microbial populations are called microbialites. Their formation depends on both environmental and biological parameters, similarly to eukaryotic skeletal carbonates and therefore raise similar questions. Stromatolites i.e laminated microbialites, are particularly emblematic geobiological materials since they are the oldest evidence of life-mineral interactions, dated up to 3.5 Gyrs ago ${ }^{1}$. However, while their environment formation is interpreted based on our knowledge about modern analogs, the latter remains incomplete. Recently, we discovered modern stromatolites in Mari Ermi, a coastal pond in Western Sardinia that experiences severe seasonal evaporation and large salinity variations ${ }^{2}$. Assuming that their accretion was controlled by the environment, we explored 1) the mineralogical composition of these unique sedimentary archives and their spatial variations down to the submicrometer scale to gain better insight into how mineral phases record the conditions and processes of their formation. We investigated the heterogeneous distribution of minerals using quantitative X-ray chemical maps provided by energy dispersive $\mathrm{x}$-ray spectrometry analyses coupled with scanning electron microscopy (SEM-EDXS). Hyperspectral maps were analyzed using an innovative data treatment method allowing phase recognition within the complex mineral mixtures and solid solutions encountered ${ }^{3}$. This method provided quantitative data on spatial distribution, modal content and associated calculated unit formulas for each identified mineral phase with a hundred nanometer resolution. And 2) the oxygen and carbon isotope composition of the stromatolitic laminations. We will then discuss how not only the environment but also microorganisms may drive the carbonate mineral growth and diversification of the mineral assemblages.

[1] Allwood, A. C. et al. (2007), Precambrian Research 158, 198-227.

[2] Saint Martin, J.-P. \& Saint Martin, S. (2015a), Geo-EcoMarina 21, 35-53. 